\title{
結晶構造の不規則性に基づく $\mathbf{X}$ 線の \\ 散漫散乱について (I)*
}

垯火理场理欧室松原武生

昭和 23 年 7 月 19. 白受領)

\section{On the Diffuse Scattering of X-Rays by a Partially}

\section{Ordercd Crystal. Part I}

Takeo MATSUBARA, Physical Institute, Osaka Úniversity

A general theory of the diffraction phenomena of $\mathrm{X}$-rays by a crystal having irregularities of its atomic arrangements has been developed. First, the intensity formula was written as a sum of three terms, having distinct meanings: the first term represenț a normal Laue pattern, the second a diffuse pattern similar to that due to a gas, and the third an anomalous Laue pattern. The third term is that whith we are most interested in, and is due to the correlations between the irregularities possessed by any two lattice points. It is a function $r(b)$ of the reciprocal lattice vector $b$, being given by equation (2.8) . It can be concluded that the weight of the scattering power for it is in general concentrated near the reciprocal lattice points, so that it gives a diffuse pattern lying near the normal Laue spots. Explicit calculation of $J(b)$ was carried out for two cases: (1) the irregularities are due to lattice vibrations (obtaining Waller's formula in a more exact form) and (2) they are due to the order-disorder arrangements of the atoms in an alloy of the type $A B$ with the simple cubic structure. In the second case, a general formula was first set up, and then Zernike's theory of the propagation of ordars was applied to represent it in a more closed form. Some aspects of the intensity of the anomalous scattering were discussed in connection with the change of the degree of orders.

\section{1. 䋨郭}

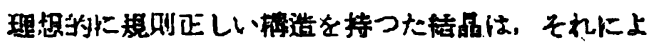

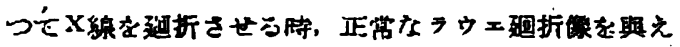

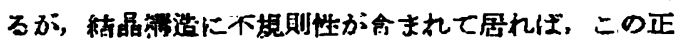

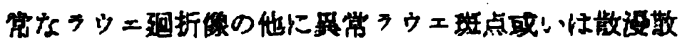

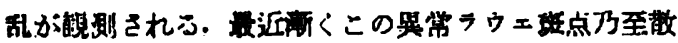

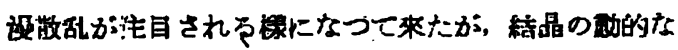

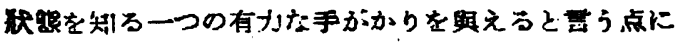

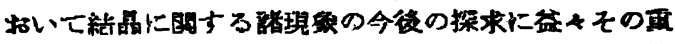

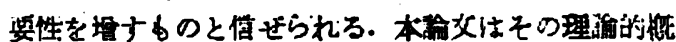

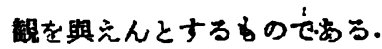

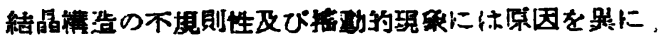

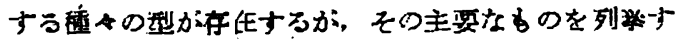

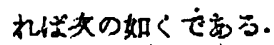

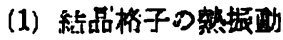

(2) 合全柔に於けっ原子政列の乱れ

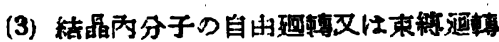

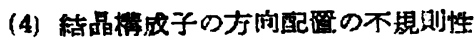

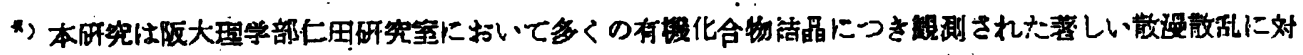

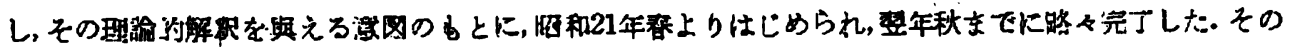

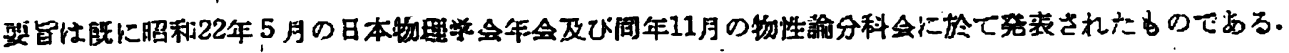
们聝时中アメリカで出版された Zachariasen: Theory of $X$-ray Diffraction in Crystals. 213 (1945).

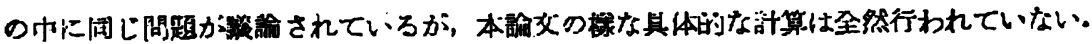


（5）格子缺陷

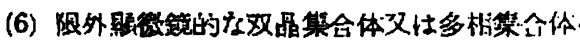

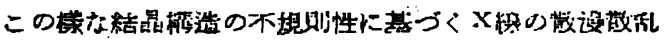

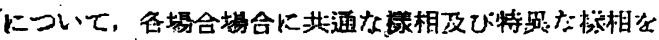

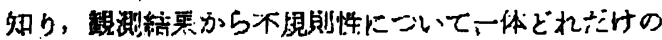

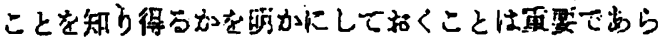
3.

\section{2. 一般的な注意}

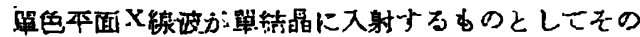

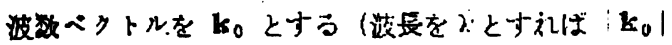

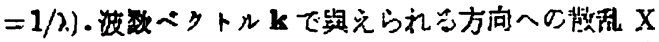

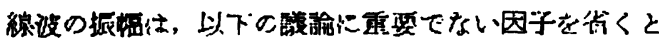
夾の $F(b) に$ に比例丁る:

$$
F(b)=\int_{\text {eryotal }}^{\rho(\mathbf{x})} e^{-2 \pi i(\mathbf{b . r})} d v .
$$

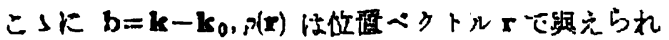

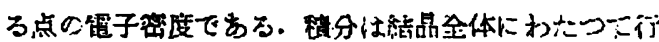

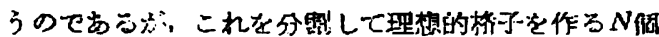

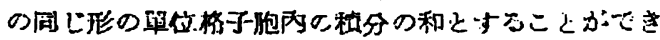
ろ. 但し理想的結昆てないものを间题にしようとする のであるから，N個の程分は一般に等しくなく赫诚 と共に不断に变化する場合。考えなければならない。 笚位格子片に番号をつけて $l=0,1,2, \cdots N-1$ とし，

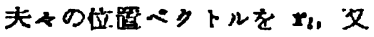

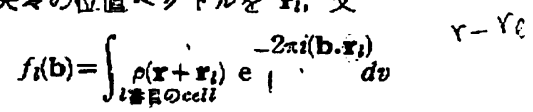

とおけば (1)注次の恕くなる：

$$
F(\mathbf{b})=\sum_{i=0}^{N-1} f_{l}(\dot{b}) \mathrm{e}^{-2-i\left(\mathbf{b} \cdot \mathbf{r}_{l}\right)}
$$

fi(b) が时间と共に势化する堨合にも，その変化は $\mathrm{X}$

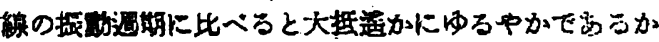

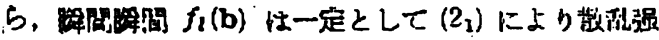
度を定めてよい：

$$
\mid F(\mathbf{b})_{1}==\sum_{k=0}^{N-1} \sum_{k=0}^{N-1} f_{k}^{i}(\mathbf{b}) f_{l}(\mathbf{b}) \mathrm{e}^{2 \pi i\left(\mathbf{b} \cdot \mathbf{x}_{k l}\right)}
$$

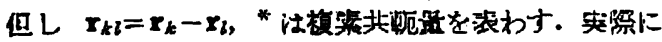

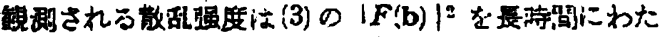

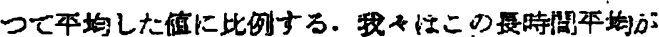

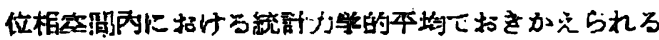

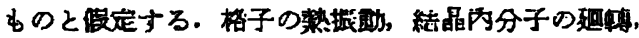

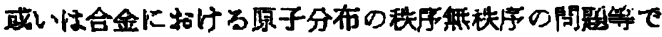
はこの種の平㘬を間题にすることになるが，勿論すへ ての場台がこの橉にして报われるわけてはない， 则人ば興えられた結晶が何らかの原因により一定の不

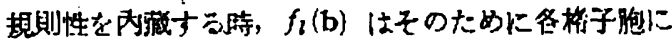
よーつ㮔なの值を取るかけであるが，その取り得る值

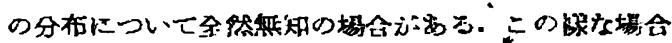
には，むしろ実铪的に知られる $|F(b)|^{2}$ からその分

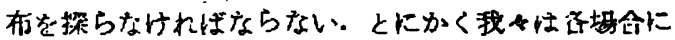

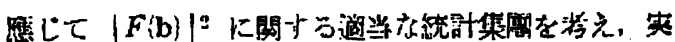

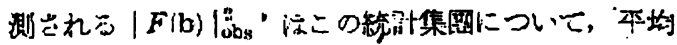
を取つたすのに等しいと考えうことにする。をして不

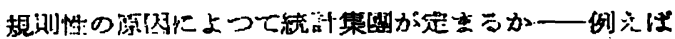

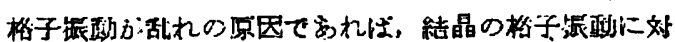
すう Gibbsのカノニカル集四を取り，此の集搮心つ

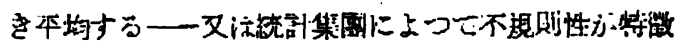

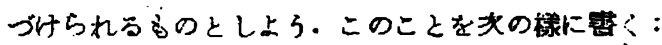

$$
\begin{aligned}
& |F(\mathbf{b})|_{\text {bbs }}^{*}=\left\langle|F(\mathbf{b})|^{2}\right\rangle \\
& =\sum_{k=s}^{N-1} \sum_{l \neq 0}^{N-1}\left\langle f_{k}^{*}(\mathbf{b}) f_{l}(\mathbf{b})\right\rangle \mathrm{e}^{2 \pi i\left(\mathbf{b} \cdot \mathbf{r}_{k l}\right) .}
\end{aligned}
$$

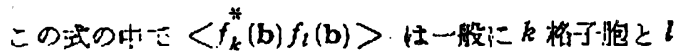

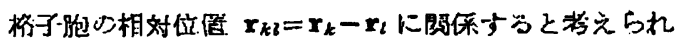

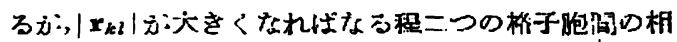
闹成保证なくなるから，

$$
\lim _{\left|\mathbf{r}_{k l}\right| \rightarrow \infty}\left\langle{ }_{k}^{*}(\mathbf{r}) f_{l}(\mathbf{b})\right\rangle=|\langle f(\mathbf{b})\rangle|^{2}
$$

と拧いて

$$
\left\langle f_{k}^{*}(\mathbf{b}) f_{l}(\mathbf{b})\right\rangle==\left.^{\prime}\langle f(\mathbf{b})\rangle\right|^{2}+\sigma\left(\mathbf{r}_{k l}\right)
$$

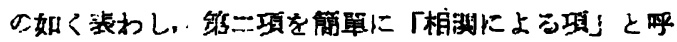
ぶことにする。すると $\left(3_{1}\right)$ は琶改めて头の三项の和と することが时肃う：

$$
\begin{aligned}
& \left\langle\left. F(\mathbf{b})\right|^{2}\right\rangle=|\langle f(\mathbf{b})\rangle| 2 \sum_{k} \sum_{l} \mathrm{e}^{2{ }^{2 \pi i}\left(\mathbf{b}^{\prime} \mathbf{r}_{k l}\right)} \\
& +N(\langle f(b)|=>|\langle f(b)\rangle ;\} \\
& +\sum_{k} \sum_{l} \sigma\left(\mathbf{r}_{k l}\right) \mathrm{e}
\end{aligned}
$$

右辺の第一项注 $\left(4_{1}\right)$ の第一项から生じ"作均された” 理想到格子に基つく散乱强度である。筑二沶注 $\left(3_{1}\right)$ の 和の的 $k=l$ の項から特に生ずる部分ですり，旌三項

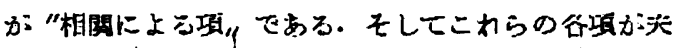

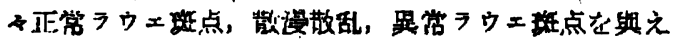
るものでむることは坊のように容易に知わる。

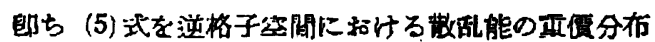

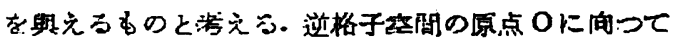

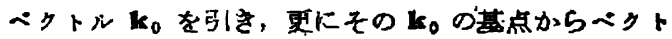

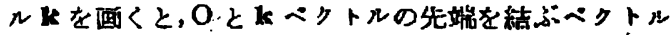
$b=k-\mathbf{k}_{0}$ の位通に忊度 (5)で與えられるげけの而

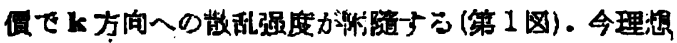
的格子の望位格子胞をきめろ基本へクトルを $\mathrm{a}_{1}, \mathrm{a}_{2}$, 


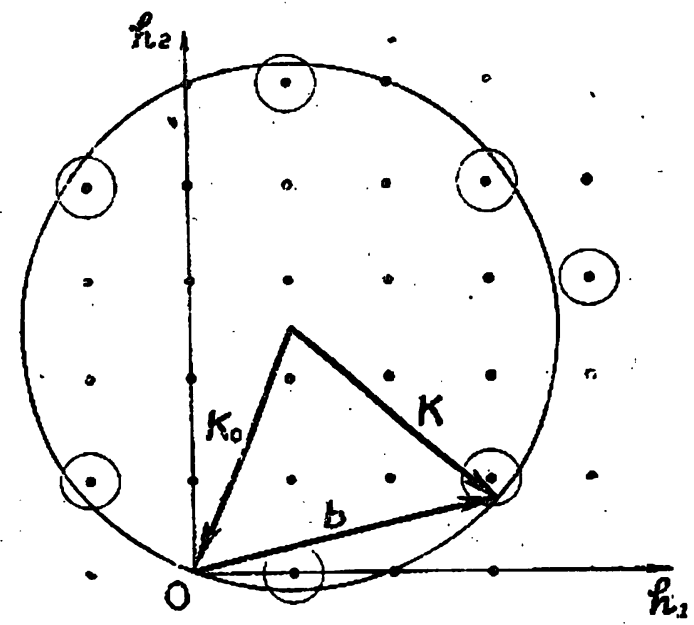

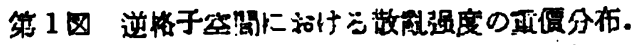

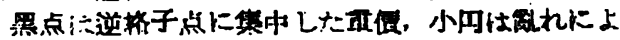

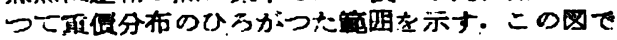

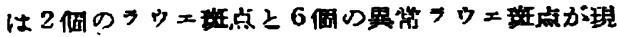
われている.

Fig. 1. A section of the reciprocal lattice space. A great circle is the reflection sphere, and the reciprocal lattice-points are shown by black points; the weight of the diffuse scattering power concentrates about each of the latter. Small circles represent these regions of this concen:ration. For the example given in this figure two normal Laue spots and six anomalous Laue spots appear.

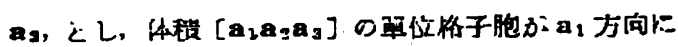

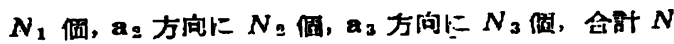

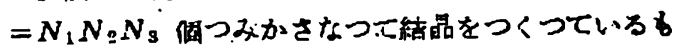
のとすれば，(5)式の第一项：土大のラウェの函敌に比例 ナる:

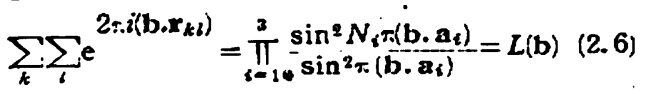
この政数仙ラウェの攸件:

$$
\begin{aligned}
& A_{i}=\left(\mathbf{b} . a_{i}\right)=h_{i} \\
& h_{i} \text { は些砤， } i=1,2,3
\end{aligned}
$$

をみたーす時，或いは逆格子べクトルて沓えば

$$
\mathrm{b}=\mathrm{B}\left(h_{1} h_{9} h_{3}\right)=h_{2} \mathrm{~b}_{1}+h_{2} \mathrm{~b}_{9}+h_{3} \mathrm{~b}_{3}
$$

$b_{1}=\frac{a_{2} \times a_{3}}{\left[a_{1} a_{2} a_{3}\right]}, \quad b_{2}=\frac{a_{3} \times a_{1}}{\left[a_{1} a_{2} a_{3}\right]}, \quad b_{3}=\frac{a_{1} \times a_{2}}{\left[a_{1} a_{2} a_{3}\right]}$ で與穴られる迹格于点 $\mathbf{B}\left(h_{1} h_{2} h_{3}\right)$ をbヘクトルが指 す特にのみ大きい值 $N$ :を取り，それ以外のbに対し

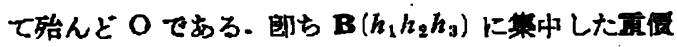

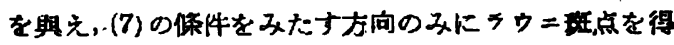
ろ. (5) の第二項は一般にbの酸としてゆるやかに 变化し，逆格子等間內にひろがつ分布をすろ. 特に

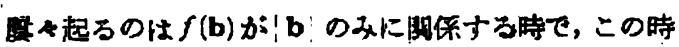

にはk。ヘクトルを軸として|b|て定まう牛頂角をは さむ网然上にのるkヘクトルのう向にはナべて同一强

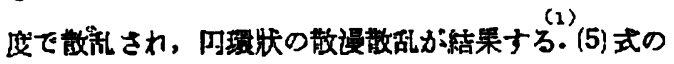

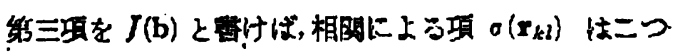
の格子点の相対位典のみに成你すると見てよいから二 面教数の和の一方は近似福に省けて $k, l$ の一方を原点 に固定した時の和の $N$ 倍としてよい：

$$
\begin{aligned}
f(\mathbf{b}) & =\sum_{k} \sum_{l} \sigma\left(\mathbf{r}_{k l}\right) \mathrm{e}^{2 \pi i\left(\mathbf{b} \cdot \mathbf{r}_{k l}\right)} \\
& =N \sum_{l} \sigma\left(\mathbf{r}_{l}\right) \mathrm{e}^{-2 \pi i\left(\mathbf{b} \cdot \mathbf{r}_{l}\right)}
\end{aligned}
$$

(8)はb の函数として(6)よりりはすかかに（5)の第二:

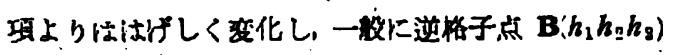

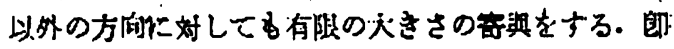
ち厚常ラシニ琣点を與えるわけである。

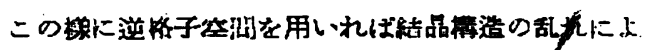

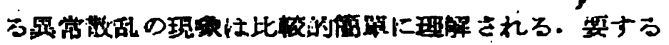

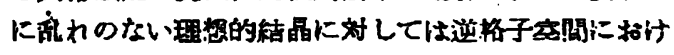

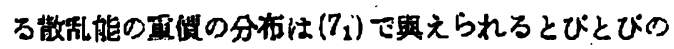

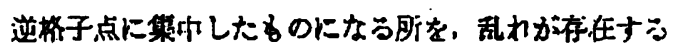
ためにこの壆中した分布が隌けて，逆格子点以外收。

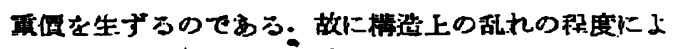

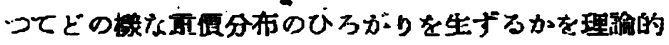

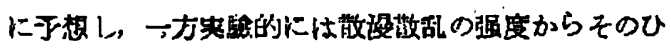

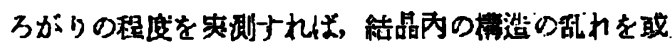
程度推定し得ることになる。併し。( $\left.\mathbf{x}_{k l}\right)$ を求め，更 に(8）に上つて $J(b)$ を計算するといること海易て 法ないまとまつた $J(\mathbf{b})$ の表式が得られる具体的な 列については後の斯にゆずることにし，ここでは (8) について一股的に宣える事唡を注意するにととめよ

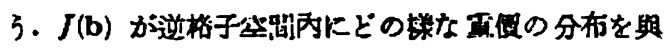

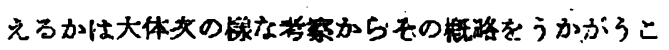

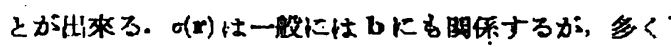

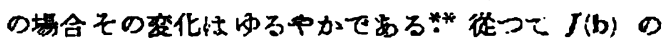

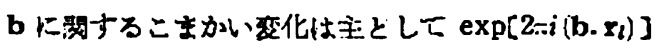

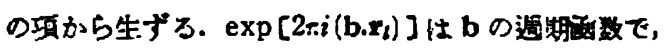
b を $\mathrm{b}+\mathbf{B}\left(h_{1} h_{2} h_{3}\right)$ に戕えてもその值を变えない.

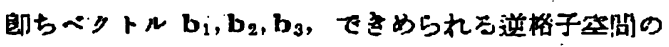

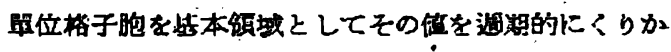
えナ.このことから (8) の和はその振幅をゆるやかた

*こ」での $(-\mathbf{r})=\sigma(\mathbf{r})$ 即ち好程中心の存在を假定

** $\sigma(\mathbf{r})$ は $f(\mathbf{b}) \leq \int_{u_{n l t} \text { cell }} \rho(\mathbf{r}) \mathrm{e}^{-2 \pi i(\mathbf{b} . \mathbf{x})} d v$ を通して

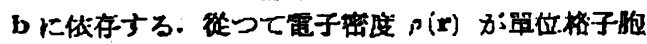
中の张、领城に集中している泉な塔合には。(r)は b の函敕として鬼めてゆろやかに变化する。 


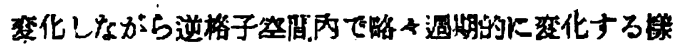
な西数でることが知れる。ところが(6) で興えられ

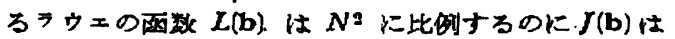

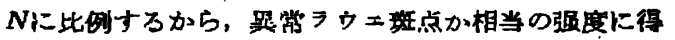

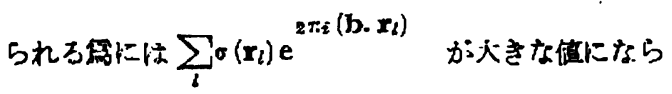

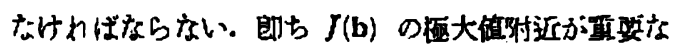
奋與をすることになる. 何処に $J(b)$ の函大值か現わ れるかは $\sigma\left(\boldsymbol{x}_{l}\right)$ の形が與えられないときまらないが,

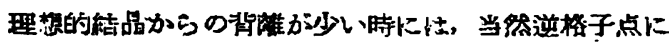
集中した其便の周围にわ亏゙かたひろがつた西價分布を

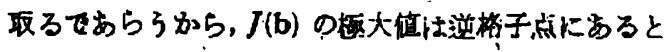
見なされら.このことはその乱れの絊とは算閶保に， 與えられた結晶によつて與えられた波長の入線を迴折 させる時に現わるべき党ラウェ斑点の炎体の位置を 知ろのに役立つ. 即ち第 1 因の如く ○に闶つて引いた

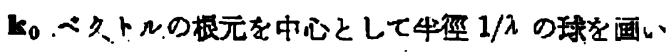

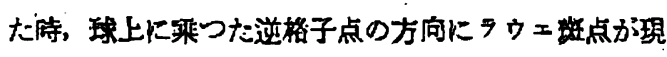

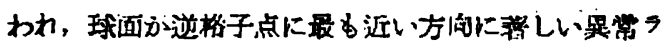
ウェ点が現われるのである。

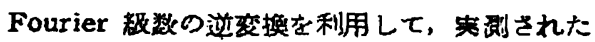

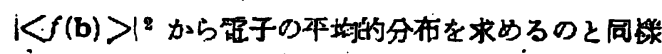
にして, $J(\mathbf{b})$ ，の实揤值か门 $\sigma\left(\mathbf{r}_{t}\right)$ を求めることは出

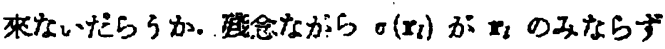

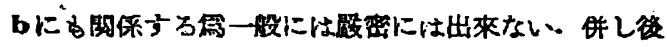
にもその例が出て來るのであるか。 。( $\left.\boldsymbol{r}_{i}\right)$ がbだけの 㖤 $g(b)$ と $\mathbf{r}_{b}$ t゙けの函数 $\sigma^{\prime}\left(x_{l}\right)$ の程に分れ

$$
\sigma\left(\mathbf{b} . \mathbf{r}_{l}\right)=g(\mathbf{b}) \sigma^{\prime}\left(\mathbf{r}_{l}\right)
$$

の形になる時には

$$
J(b) / N g(b)=\sum_{l} \sigma\left(x_{i}\right) e^{-2 \pi i\left(b \cdot x_{i}\right)}=\Xi(b)
$$

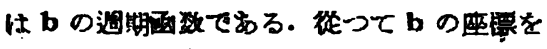

$$
b=u b_{1}+v b_{2}+w b_{3}
$$

によつて皆入すると

$$
J(u v w) / N g(u v w)=\Xi(u v w)
$$

$$
=\sum_{l_{1}} \sum_{l_{2}} \sum_{l_{3}} \sigma^{\prime}\left(l_{1} l_{2} l_{3}\right) \mathrm{e}^{-2 \pi i\left(u l_{1}+v l_{2}+w l_{3}\right)}
$$

そなり，荑㯺的にJ(uvv) 及び $g(u v w)$ を定めること かでれば上政から

$$
{ }^{\prime}\left(l_{1} l_{2} l_{3}\right)=\iiint \Xi(u v w) \mathrm{e}^{2 \pi i\left(u l_{1}+v l_{2}+w l_{3}\right)} d u d v d w
$$

によつて 生 $\left(l_{1} l_{2} l_{3}\right)$ を決定することが出來ろ.

\section{3. 格子振動の影響}

結晶格于の熱振野に上つて生ずろ格子の乱れは散漫 敖乱の原因としては最り替通のすのである.從つて理
論的にも旧くから最近に至るまで多くの等者によつて

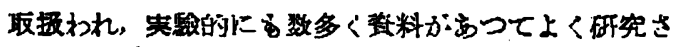

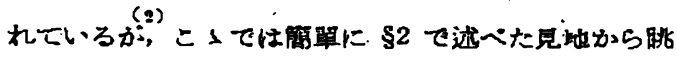
めな扎して見る: 简單のため陮一種の原子が戰級格子 を作つている场合を考光，原子灀造因子を $f(b)$ ，各原 子核の厈很位置からの变位を $\mathbf{u}_{b}(l=0.1 \cdots N-l)$ とす れ位, (2)の $f_{l}(\mathbf{b})$ 江

$$
f_{3}(b)=f(b) \mathrm{e}^{-2 \pi i\left(b \cdot u_{l}\right)} .
$$

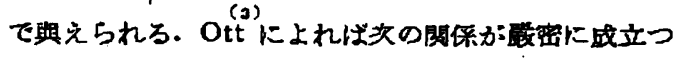

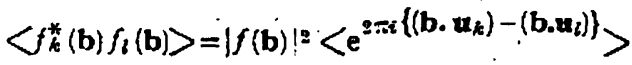

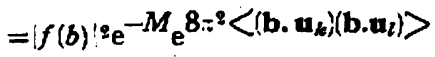

但し

$$
M=8 \pi^{2}\left\langle(b . u)^{2}\right\rangle
$$

け Debye-Waller の调度因子である.| $\mathbf{r}_{k t} \mid \rightarrow \infty$ と其

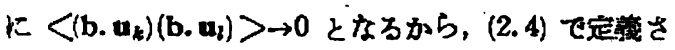
れる $\sigma\left(\mathbf{x}_{k l}\right)$ 恃今の揚合

$$
\sigma\left(\mathbf{x}_{k l}\right)=\mid f(\mathbf{b})_{1}^{2} \mathrm{e}^{-M}\left\{\mathrm{e}^{\left.\mathrm{gr}^{2}<\left(\mathbf{b} . \mathbf{u}_{k}\right)\left(\mathbf{b} . \mathrm{u}_{k}\right)>-1\right\}}\right.
$$

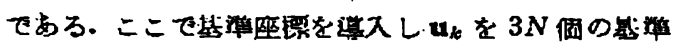
振動で藏わす：

$$
\mathbf{u}_{k}=\sum_{j=1}^{3} \sum_{\mathbf{q} \cdot} A g(\mathbf{q}) e_{j}(\mathbf{q}) e^{2 \pi i\left(\mathbf{q} \cdot \mathbf{x}_{k}\right)}
$$

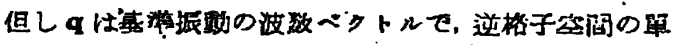

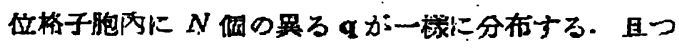

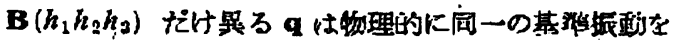

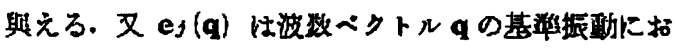
ける原子の振跑方㘬を示寸單位ベクトルであり，一 のqに対し三つの豕ろ互に直交した方向 $\mathbf{e}_{1}, \mathbf{e}_{2}, \dot{e}_{3}$, が可能源，これらを $j=1,2,3$ で区別する. 即ち合㖕

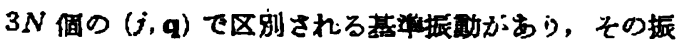

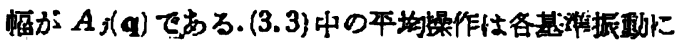

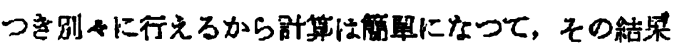
は例えば丈の楾になる：

$$
\begin{aligned}
& P\left(\mathbf{r}_{k l}\right) \equiv 8 \pi^{2}<\left(\text { b. } \mathbf{u}_{k}\right)\left\langle\left(\mathrm{b} . \mathrm{u}_{l}\right)\right\rangle \\
& =8 \pi: \sum_{j} \sum_{\mathbf{q}}\left\langle\left|A_{j}(\mathbf{q})\right|^{2}\right\rangle\left(\text { h. e }_{j}(\mathbf{q})\right)^{2} \mathrm{e}^{2 \pi i\left(\mathbf{q} \cdot \mathbf{x}_{k l}\right)} \\
& M=8:^{2}\left\langle\left(\mathrm{~b} . \mathrm{u}_{k}\right)^{2}\right\rangle=P(0) \\
& =8 \pi^{2} \sum_{j} \sum_{\mathbf{q}}\left\langle A_{j}(\mathbf{q})^{2}{ }^{2}\right\rangle\left(\mathrm{b}_{.} \mathrm{e}_{j}(\mathrm{q})\right)^{2} \\
& \text { (?) }
\end{aligned}
$$

* Ott の但子力学的な愺算結果K上れば, (3) $e^{P(\mathbf{r})}$

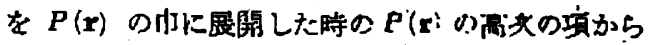
生ずる教乱は，X線が二盾以上の基微振野を同時に。 酸起して敬乱されることに相当し，それらの散乱强 度は非常に小さい。 


$$
\begin{aligned}
& J(\mathbf{b})=\sum_{k}^{\prime} \sum_{i} \sigma\left(\mathbf{r}_{k l}\right) \mathrm{e}^{-2 \pi i\left(\mathbf{b} \cdot \mathbf{x}_{k l}\right)} \\
& \approx|f(\mathbf{b})|=\mathrm{e}^{-M} \sum_{k} \sum_{i} P\left(\mathbf{r}_{k l}\right) \mathrm{e}^{-2 \pi i\left(\mathbf{b} \cdot \mathbf{r}_{k l}\right)} \\
& =8 \pi^{2} \mid f(b)_{1}^{2} e^{-M} \sum_{j} \sum_{q}\left\langle_{i} A_{j}(q)^{2}\right\rangle\left(b_{0} e_{J}(q)\right)^{2} L(b-q) \\
& -! f(\mathbf{b}) \mid=\left(1-\mathrm{e}^{-M}\right)
\end{aligned}
$$

となろ.最後に整引いてある部分は(2.5)式の右边第 二項に相当する。

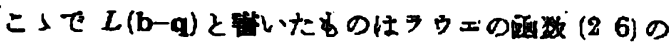
bの代らにb-q とおいたすのである.これは b-q

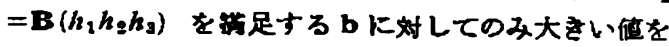
取り，それ以外怡んど ○である．故に(17)の結果 を头の等迅へることが出來る：

「與えられた b方向への

$$
\mathbf{b}=\mathbf{q}+\mathbf{B}\left(h_{1} h_{2} h_{3}\right)
$$

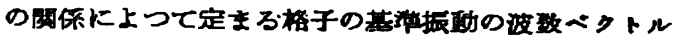
を qとすれば

$$
8 \pi^{2} \mid f(b) j^{2} e^{-M} \sum_{j=1}^{3}\left\{(\text { b.e e }(q))^{2}\left\langle\left|A_{j}(q)\right|^{2}\right\rangle\right\}
$$

に比例子る.」

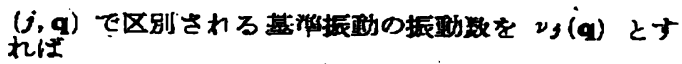

$$
\begin{aligned}
& \left\langle A_{j}(\mathbf{q})_{i^{2}}\right\rangle=\frac{1}{2 \pi^{2} m \nu_{j_{j}}(\mathbf{q})} \\
& \quad \times\left\{\frac{h \nu_{j}(\mathbf{q})}{\exp \left(\frac{h \nu_{j}(\mathbf{q})}{k T}\right)-I}+\frac{1}{2} h \nu_{j}(\mathbf{q})\right\}
\end{aligned}
$$

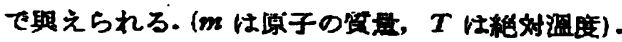
q〜0に対し に上り $J(b) /|f(b)| \cdot \cdot$ : $\mathbf{q}=0$ 郎古 $\mathbf{b}=\mathbf{B}\left(h_{1} h_{3} h_{3}\right) k$

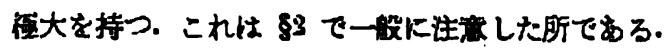

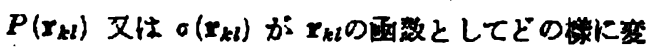
化するかを槆べることは理路的に興倲梁いことであ

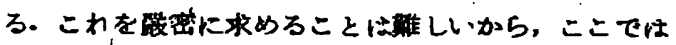

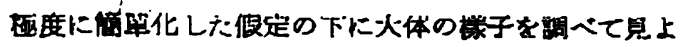

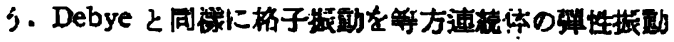

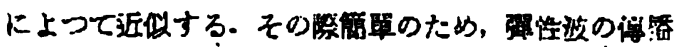

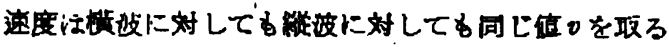
ののとする. 即ち $|q|=\nu / v$ でる. 又るす $x_{k l}$ も一

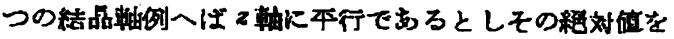

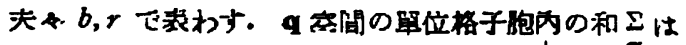

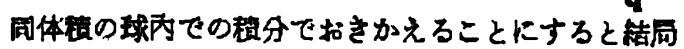
买の如くなる：

$$
\begin{aligned}
P(v) & =\frac{b^{2} V}{m v^{2}} 2 \pi k T \\
& \times \int_{0}^{\nu \max } d \nu \int_{0}^{\pi} d \theta \sin \theta \Phi\left(\frac{h \nu}{k T}\right) \cos \left(2 \pi \frac{v \nu}{v} \cos \theta\right)
\end{aligned}
$$

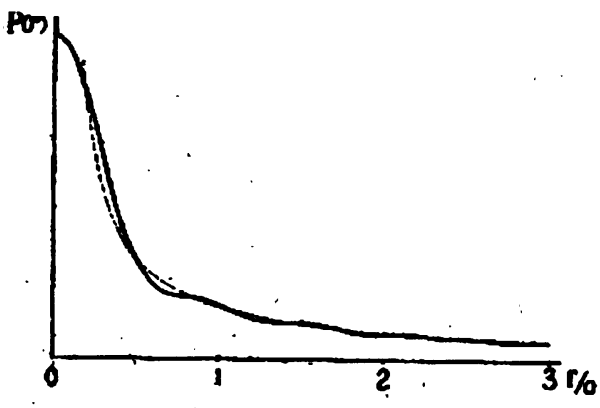

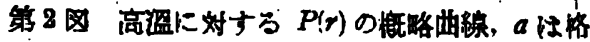
子常数，破線任 $1 / 1$ の曲楾である。

Fig. 2. A sketch of the curve for the $P(r)$ function at a high temperature. $a$ is the lattice constant. The broken curve is $1 / r$

こょ

$$
\Phi(x)=\left\{\frac{x}{\mathrm{e}^{x \rightarrow 1}}+\frac{x}{2}\right\},
$$

Vは結晶の体础でる。のについて樻分を行つて头を 得乃:

$$
\begin{aligned}
& P(r)=\frac{2 b^{2} V}{m v^{2}} \frac{k T}{\gamma} \int_{0}^{x_{m}}\left\{e^{x}-1+\frac{x}{2}\right\} \frac{\sin \mu x}{x} d x \\
& \mu=\frac{2 \pi k T r}{h v_{4}}, x_{m}=\frac{h \nu_{\max }}{k T}={ }^{-}{ }^{-} \mathrm{D}
\end{aligned}
$$

然 2 四には(3.10) から求められる $P(y)$ をの画数と して凶示しだこの因から結昆內の原子の振㗢の $(\mathbf{2 . 4})$

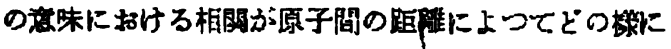
积り交わるか大体らかがえるであらう。

\section{4. 合金系における原子界列の㓩れに基つく} 散漫散期

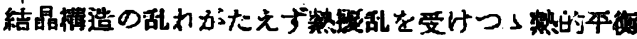
にある場合の散温数乱の强度式を求めることは至く統

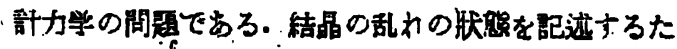

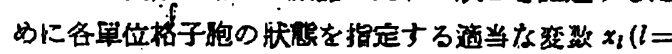

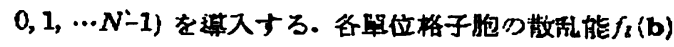
は $x_{l}$ の函数である。

$$
f_{l}(\mathbf{b}) \doteq f\left(\mathbf{b} ; x_{t}\right)
$$

結晶の取り得る一つの狀照 $\left(x_{0} x_{1} \cdots x_{N-1}\right)$ 犬英現され

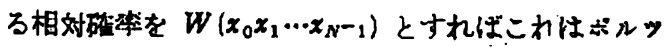
マンの定理によつて

$$
W\left(x_{0} x_{1} \cdots x_{v-1}\right)=\exp \left[-E\left(x_{0} x_{1} \cdots x_{N-1}\right) / k T\right]
$$

で與えられる.こつに $E\left(x_{0} x_{1} \cdots x_{N-1}\right)$ は狀照 $\left(x_{0} x_{1} \cdots x_{N-1}\right)$ の柔のエネルキーであう. 故に \$2に

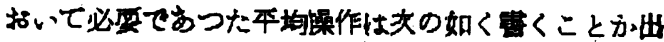
來る:

$$
\left\langle f_{k}^{*}(\mathbf{b}) f_{l}(\mathbf{b})\right\rangle=\frac{\sum_{(\boldsymbol{v})} W\left(x_{0} x_{1} \cdots x_{N-1}\right) f^{*}\left(x_{k}\right) f\left(x_{l}\right)}{\sum_{(x)} W\left(x_{0} x_{1} \cdots x_{N-1}\right)}
$$

(4.1) 
ここに $\Sigma_{(x)}$ は $\left(x_{0} x_{1} \cdots x_{N-1}\right)$ の钎されるすべての值につ いて和を取ることを意昧占る。こって

$$
P_{k i}\left(x x^{\prime}\right)=\sum_{(x)}^{\prime} W\left(x_{0} \cdots x_{N^{\prime}-1}\right) / \Sigma W\left(x_{0} \cdots x_{N-1}\right)
$$

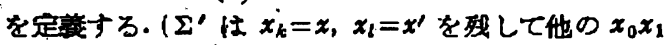

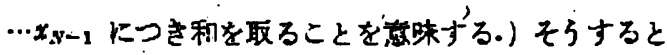
(4.1) 仕

$$
\left\langle f_{k}^{*} f_{i}\right\rangle=\sum_{x=z^{\prime}} P_{k l}\left(x x^{\prime}\right) f^{*}(x) f\left(x^{\prime}\right)
$$

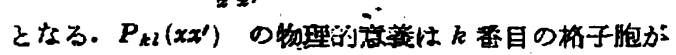

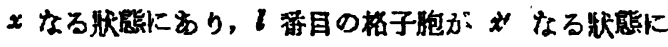
あることの政害であるが，(4.2) を計算しそれから散 㗄散讯の虽度式 $J(b)$ を求めるにはこの $P_{k l}\left(x x^{\prime}\right)$ 方

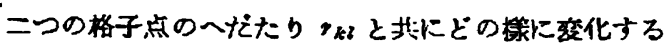

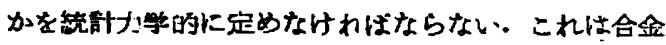

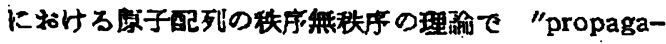
tion of order"の閶题として特に最近理諭物理学者の 注目を浴びているるのであり,これについてはいくつ

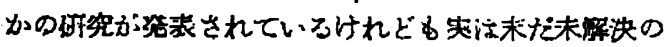

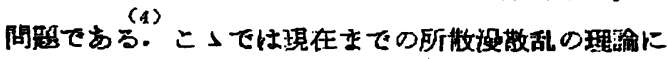
最す通した形に展開されている Zernike の理确に從

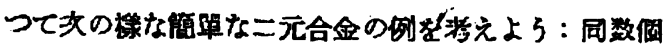
の $\mathrm{A}, \mathrm{B}$ 二拜の原子から成る單純立方格子の合会が,

A原子と $\mathrm{B}$ 原子を交互に $\mathrm{NaCl}$ 㤠格子の如く配置した 完全秩店の狀態から，原于配列の全〈乱鞋な完全無秋

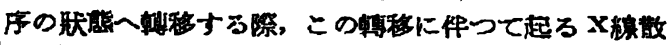
乱腽度の変化を問题にする. 完全秩度の際にA原子が 占める小格子の点を $\alpha$ 究， $\mathrm{B}$ 原子が占めるそれを $\beta$ 需 と名づける.

' $f_{\mathrm{A}}, f_{\mathrm{B}}$ を头 $\mathrm{A}$ 原子、B 原子の原子散乱能とし, 变数 $x_{i}$ 仕 格于点が A 原子で占められる時 $+1, \mathrm{~B}$ 原子て占められる時 -1 ときめると $f_{l}(b,+1)=f_{A}$, $f_{b}(b,-1)=f_{B} ;$ 從つて (4.2) 式仙

$$
\begin{aligned}
\left\langle f_{k} f_{i}\right\rangle & =f_{\mathrm{A}^{3}} P_{k l}(1,1)+f_{\mathrm{B}}^{2} P_{k l}(-1,-1) \\
& +f_{\Delta A \mathrm{~B}}\left(P_{k l}(1 ;-1)+P_{k l}(-1,1)\right)
\end{aligned}
$$

となる. $P_{k l}( \pm 1, \pm 1)$ は $k, l$ が $\alpha$ 席か $\beta$ 席かに上

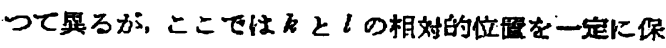
ちながら $k$ を結晶全体に移欧させて $P_{k l}( \pm 1, \pm 1) の$ 平均をとつたりのを政めて $P_{k b}( \pm 1, \pm 1)$ と雷くこと にする.これは $k$ に無開保であつて， $k=0$ と夏いて む上い.そろすると明らか比

$$
\begin{aligned}
& P_{k l}^{-}(1,1)+P_{k l}(1,-1)=\frac{1}{2}, \\
& P_{k l}(-1,1)+P_{k l}(-1,-1)=\frac{1}{2}, \\
& P_{k l}(1,1)+P_{k l}(-1,1)=\frac{1}{2}, \\
& P_{k l}(1,-1)+P_{k l}(-1,-1)=\frac{1}{2} .
\end{aligned}
$$

なる睅保が成立つから，例元ば $P_{k z}(1.1)=P_{k l}$ を用い て残り三つの $P_{k l}$ を表わすことが出來，それを」式に 持込をことにより头式が得られる：

$$
\left\langle f_{k} f_{i}\right\rangle=\left(f_{A}-f_{B}\right)^{2} P_{k l}+f_{A A B}
$$

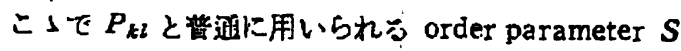

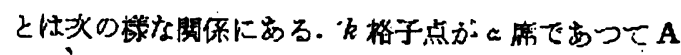
原子で占められている壯にのことを $\frac{1}{2} \times \frac{1}{2}(1+S)$

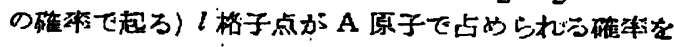

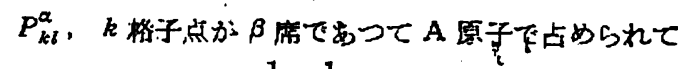
いる時(このことは $\frac{1}{2} \times \frac{1}{2}(1-S)$ の確整て起る) l格 子点尤 $\mathrm{A}$ 原子で占められる礁䂾を $P_{k l}^{\beta}$ とすれば

$$
P_{k l}=\frac{1}{4}(1+S) \dot{P}_{k l}^{\alpha}+\frac{1}{4}(1-S) P_{k l}^{\beta}
$$

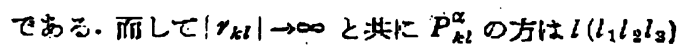
松子点分: $k\left(k_{1} k_{2} k_{3}\right)$ 格子点と闹一喠類の a席である ，封 $\frac{1}{2}(1+S)$ ，そろでない時 $\frac{1}{2}(1-S)$ 飞近づき, $P_{k l}^{\beta}$ の 万红 $l$ 格子点吕 $k$ 格子点乙同しく $\beta$ 席なら $\frac{1}{2}(1-S)$, そうでなければ $\frac{1}{2}(1+S) に$ に近づく、或いはこれを まとめて

$$
\left.\begin{array}{l}
\lim _{\left|\gamma_{k l}\right| \rightarrow \infty} P_{k l}^{\alpha}=\frac{1}{2}\left(1+(-1)^{\varphi_{k l}} S\right) \\
\lim _{\left|\gamma_{k l}\right| \rightarrow \infty} P_{k l}^{\beta}=\frac{1}{2}\left(1-(-1)^{\varphi_{k l}} S\right) \\
\varphi_{k l}=\left(l_{1}-k_{1}\right)+\left(l_{2}-k_{2}\right)+\left(l_{3}-k_{3}\right)
\end{array}\right\} .
$$

と括けば $\lim _{\mid \gamma_{k l \rightarrow \infty} \rightarrow \infty} t_{k l}^{ \pm}=0$ であつて* (4.3) (4.4) に 上つて $\left\langle f_{k} f_{i}\right\rangle$ は沃の如くなる。

$$
\begin{aligned}
& \left\langle f_{k} f_{i}>=\left(\frac{f_{A}+f_{B}}{2}\right)^{2}+\left(\frac{f_{A}-f_{B}}{2}\right)^{2} S^{2}(-1)^{\varphi_{k l}}\right. \\
& \quad+\left(\frac{f_{A}-f_{B}}{2}\right)^{2}\left(1-S^{2}\right)(-1)^{\varphi_{k l}} \frac{1}{2}\left(t^{+}{ }_{k l}+t^{-}{ }_{k l}\right)(4.7)
\end{aligned}
$$

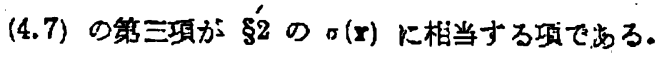

$\left(2.3_{1}\right)$ 代を用いて $\langle|F(b)| 2\rangle$ を副算すると，

$$
\begin{aligned}
& \quad\left\langle|F(b)|^{2}\right\rangle=\left(\frac{f_{A}+f_{B}}{2}\right)^{2} L\left(A_{1} A_{1} A_{3}\right), \\
& +\left(\frac{f_{A}-f_{B}}{2}\right)^{2} S^{2} L\left(A_{1}+\frac{1}{2}, A_{2}+\frac{1}{2}, A_{3}+\frac{1}{2}\right)+J(b)
\end{aligned}
$$

の形になる。第一填恃逆格子点 $\mathrm{b}=\mathbf{B}\left(h_{1} h_{2} h_{3}\right)$ に集

*少 $t_{k l}^{+}+t_{k l}^{-} \geq 0$ が期待される. 
中した酸分布で，これは本妁の散乱能 $\frac{1}{2}\left(f_{A}+f_{R}\right)$ を

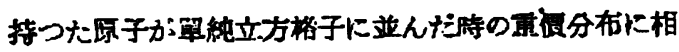

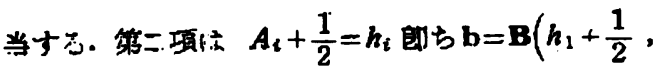
$\left.h_{2}+\frac{1}{2} ; h_{3}+\frac{1}{2}\right)=\sum_{i=1}^{3}\left(h_{i}+\frac{1}{2}\right) b_{i}$ K集虾した正假分 布を與え $\Lambda, B$ 原子吕; long ronge order $S$ て與え られら柣序正しさてるつて卡な面心立方格于根造をと

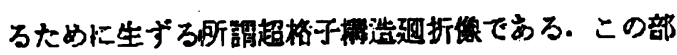

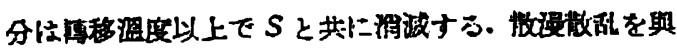

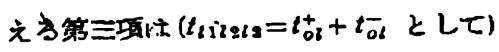

$f(b)=N\left(\frac{f_{A}-f_{B}}{2}\right)^{2}\left(1-S^{2}\right) \sum_{l 12263} t_{311223 \mathrm{e}} \mathrm{e}^{-2 \pi i \sum_{\nu=1}^{3}\left(A_{\nu}+\frac{1}{2}\right) l_{\nu}}$

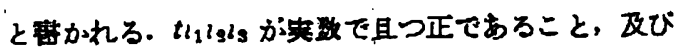

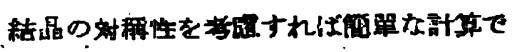

$$
\begin{aligned}
& J(b) /\left(f_{A}-f_{B}\right)^{2} \text { - } \\
& A v+\frac{1}{2}=h \nu \text { (a) } \nu=1.2 .3 \text {. }
\end{aligned}
$$

に対して㮌六值を持つことが示される. 即ち

$J$ (b) / $\left(f_{A}-f_{B}\right):$ は丁度超格子か形成されろ時に藏 格子空闻に集中した便便を生ずる

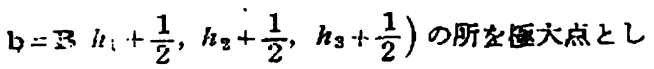

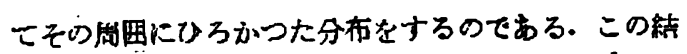
果は\$2に一一般的に注意した桹に当然朋待されると ころである. 移点以上では $S=0$ であるが局所的

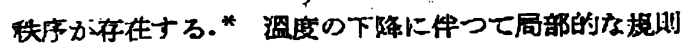
悔か次篗に生長して行くにつれて $J(b)$ は逆格于点

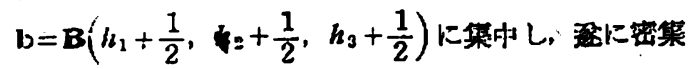

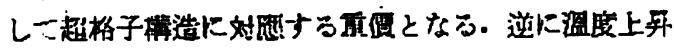

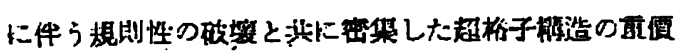
は周目汇汇けて行つて $J(b)$ を舆えるのである.この

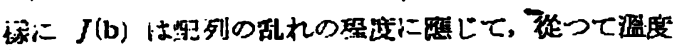
に上つてその分布を変化なる． AuCus の堵合には電

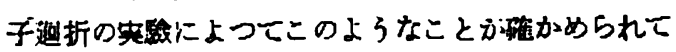

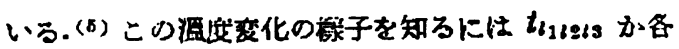

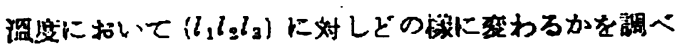

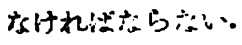

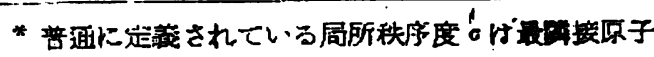
堅の配列秩序度て，我なの歌易では

$$
n=S^{2}+\frac{1}{2}\left(1-S^{2}\right)\left(t_{100}^{+}+t_{100}\right)
$$

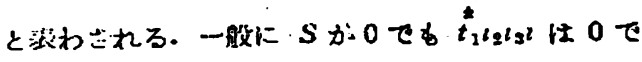

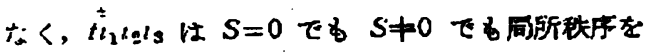

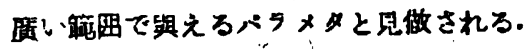

Zernike は原点にA 原子かあることを知つている

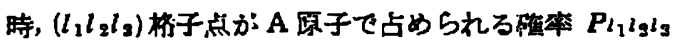

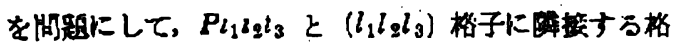
子点が A 原子で占められる確策(それ簡算に $P_{1} P_{2}$ $\cdots P_{6}$ とする)とを結びつける方品式を $P_{1}, P_{2} \cdots, P_{6}$

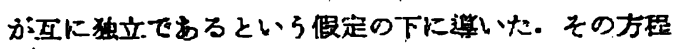
式を通当な境界保件で解けばよいのであらが，Sがー 定の溫度の函数である時には丁度 (4.5) の终件をみた 万㭌 $P_{0 l}^{\alpha}, P_{0 l}^{\beta}$ が存在することが示される. Zernike の基本方程式を(4.6)の期保によつてて $t_{0 l}^{ \pm}$に対するす 程式に㮃換するとそれは方の形になる：

$32 t^{t_{2122 t 3}}=K_{1}( \pm S)\left[t \pm_{1}\right]$

$$
\begin{aligned}
& +(1 \pm S) K_{2}( \pm S)\left[t \pm_{1} t_{9}\right] \\
& +(1 \pm S)^{2} K_{3}( \pm S)\left[t^{ \pm} t^{ \pm} t^{ \pm} \pm_{3}\right] \\
& +(1 \pm S)^{3} K_{4}( \pm S)\left[t^{ \pm} t^{ \pm} t_{2} t_{3} t^{ \pm}\right] \\
& +(1 \pm S)^{4} K_{6}( \pm S)\left[t^{ \pm} t^{ \pm} t^{ \pm}{ }_{3} t^{ \pm} t^{ \pm}{ }_{5}\right]
\end{aligned}
$$

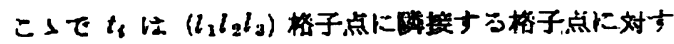
ろ $t$ を表わし［〔了注 $t$ の原数のあらゆる租合せに，

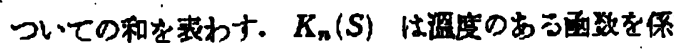

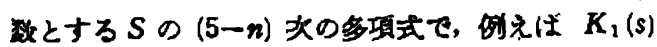
は夫の形を持つている.

$$
K_{1}(S)=K_{1}(-S)=a_{1}+10 a_{3} S^{2}+5 a_{5} S^{4}
$$

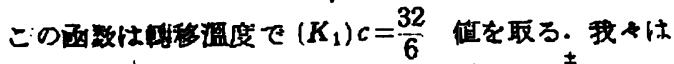

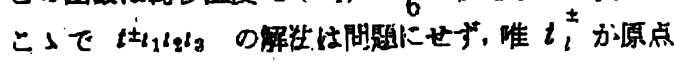

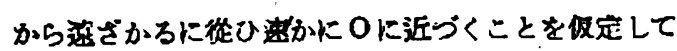

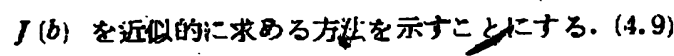
を面單に头の绿に害いておく：

$$
\dot{3} 2 t^{ \pm 16 ! l s}=\dot{K}_{1}(s) \sum_{k=1^{\prime} k}^{6} t^{ \pm}+(1 \pm S) N^{ \pm 112 l s}
$$

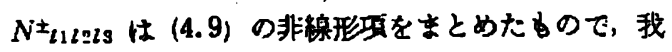

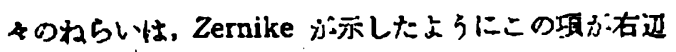

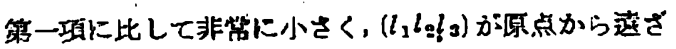
からと急に○になるということを利用しよろとするの であ.厂(b) の計斿に必要なのは

$$
I \pm=\sum_{l 12 \Omega l 3} t_{t_{1} l_{g} l_{3}} \mathrm{e}^{-2 \pi i \sum_{\nu}\left(A_{\nu}+1\right) l_{\nu}}
$$
なる和でるが，(4.10)の雨辺に $\exp \left(-2 \div i \Sigma_{\nu}\left(A_{\nu}+\right.\right.$ 市 $l_{v}$ を乘し， $l_{1} l_{2} l_{2}$ について加六合わすと近似的に

$$
\begin{aligned}
32 I_{ \pm} & \approx\left\{2 K_{1}(s) \sum_{\nu=1}^{3} \cos 2 \pi\left(A_{\nu}+\frac{1}{2}\right)\right\} I_{ \pm} \\
& +(1 \mp S) \sum_{l_{1} l_{9} l_{s}} N^{ \pm} l 1 l_{2} / 3 \mathrm{e}-2 \pi i \sum_{\nu}\left(A_{\nu}+\frac{1}{2}\right) l_{\nu},
\end{aligned}
$$

が得られる.これから头を得る：

$$
\begin{aligned}
I_{ \pm}= & \frac{(1 \mp S)}{32-2} \\
& \times\left\{N_{\nu} \frac{N_{\nu 00}+2 N_{100} \sum_{\nu} \cos 2 \pi\left(A_{\nu}+\frac{1}{2}\right)}{\left.\left(A_{\nu}+\frac{1}{2}\right)+\cdots\right\}}\right.
\end{aligned}
$$


先に迅べた理由で右辺＼{＼}中の級数性相当速加に收

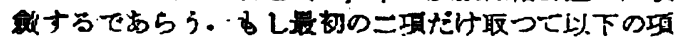
を無覞することが出來るならば

$$
\begin{aligned}
& \frac{1}{2}\left\{(1-S) N_{\nu}^{+}+(1+S) N_{\nu}^{-}\right\}=N \nu \text { と琶いて (4.8) より } \\
& J(\mathrm{~b})=\frac{\frac{N}{4}\left(1-S^{2}\right)\left(f_{A}-f_{B}\right)}{32-2 K_{1} \sum_{\nu} \cos 2 \pi\left(A \nu+\frac{1}{2}\right)} \\
& \times\left[N_{000}+2 N_{100} \sum_{\nu} \cos 2 \pi\left(A \nu+\frac{1}{2}\right)\right]
\end{aligned}
$$

を得る. $J$ は $\sum_{\nu=1}^{3} \cos 2 \pi\left(A \nu+\frac{1}{2}\right) の み に$ 望係し，正想

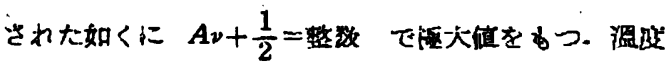

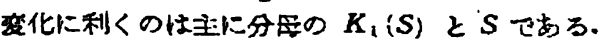

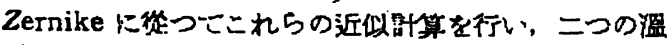
度に效して $J(b) /\left(f_{A}-f_{B}\right)=$ const $の$ 等高繶を画下 たものが第 3 冈である. (4.14) 式で注すへきは $/(b)$

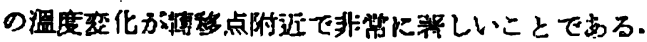

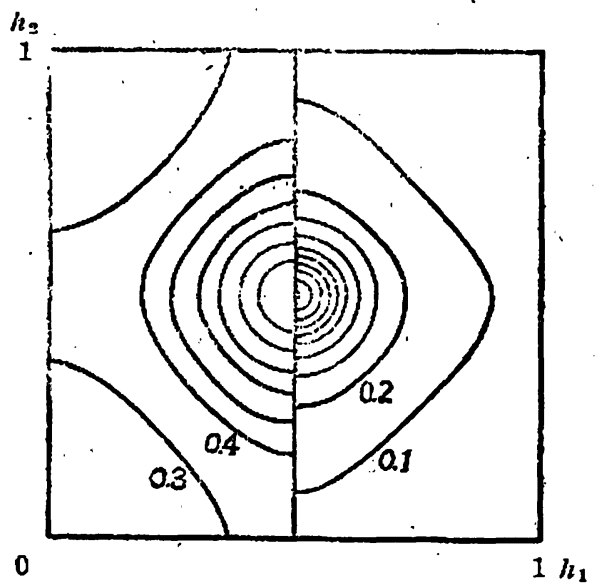

第 3 図 二元合金の场合の逆格子宝間における再僻 分有， $J(b) /\left(f_{1}-f_{B}\right)^{2}$ の等高線を示子. 中央の匪 祭は $\mathbf{B}\left(\frac{1}{2}, \frac{1}{2}, \frac{1}{2}\right)$ ，ここに極大值を取る。

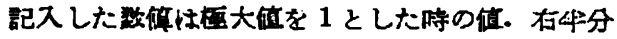
认事移点附近，左牛分俚高谓度に対了万るの.

Fig. 3. A set of iso-diffuse surface $\left(J(b) /\left(f_{A}-f_{B}\right)^{2}\right.$ =const.) in a reciprocal únit cell for the diffuse scattering due to an alloy of the ABtype with simple cuibic structure. There is a maximum of the weight at the center. The center is the point $\frac{1}{2} b_{1}+\frac{1}{2} b_{2}+\frac{1}{2} b_{3}$ of the reciprocal lattice and corresponds to the position of the super-structure lines. The numerical values assigned to the curves are the relative values, taking the Inaximum value as unity.

Right half : near the transition point.

Left half : at a high temperature above the transition point.
移点に特いては $6 K_{1}(S)=32$ が成立つが，これは

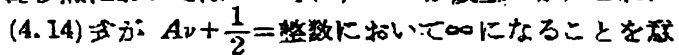

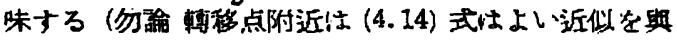

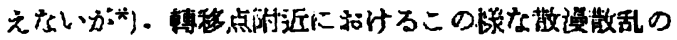

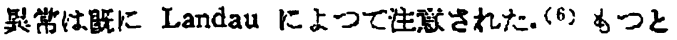

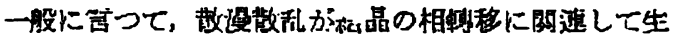

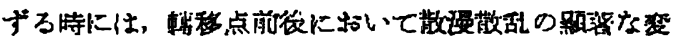

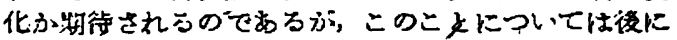

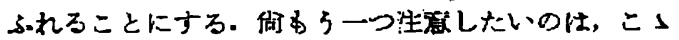
に述ぺた例は §2の終りで諭 [゙た $/(b) の$ Fourier 逆

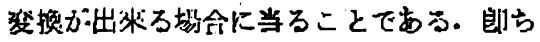

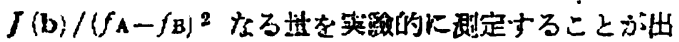
來れ代，それから逆に $t_{l_{1} l_{2} l_{3}}$ を决定することが可能 なはずてちる。 Wilchinsky が Cusu 合令について 行つた夹㧎は粉末結晶についてであつたが荚はこれに 相当した專柄空のであう.(7)

とにかく以上の取报い忙本筫的な仮定は原子間の相

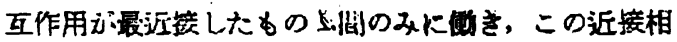

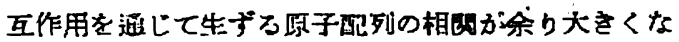
いということであう。この砥な敒定の下に得られる結

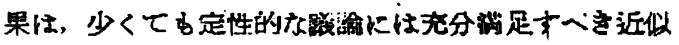
を與えると思われるが，头薜に䑙て同じ做定の下に上 述の咶算法をるら少し一般化することを铽みる。

\section{* 暗}

(未完)

(1) シクロヘキサノル，凹ニトロメタンゆ結品につい

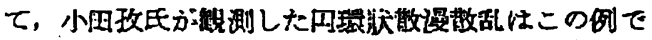

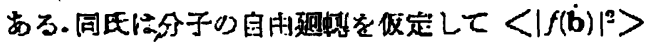

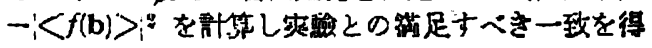
た.

小田政：X線 4，4号，2.（昍20) " 5,1.2昂, 26. (昭23)

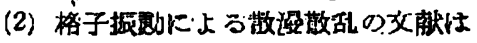

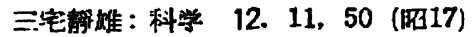

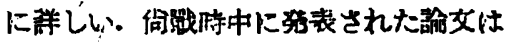

松原证生：科学 18，194（四23)

に一部收めらわてむる。

(3) H.Ott: Ann. Phys. 23, 169 (1935).

(4) F. Zernike: Physıca 7, 565 (1940);

E. N. Lasettre \& J.P. Howe :

J. Chem. Phys. 9, 747, 801 (1941);

J. Ashkin \&. W.E Lamb:

Phys. Kev. 64. 159 (1943).

(5) L. H. Germer, F.E. Haworth \&

J. J. Lander : Phys. Rev.61, 614 (1942).

(6) L. Landau: Phys. Zeits. Sowj.

12, 123 (1939).

(7) Z.W. Wilchinsky : Phys. Rev. 63, 223 (1943);

J. App. Phys. 15, 806 (1944).

*轉移点前後においては, $t_{l 12 ! 33}$ の $l_{1}, l_{2}, l_{3}$ につい ての变化か非常にゆる中かて $\left(\frac{1}{\sqrt{l_{1}^{2}+l_{2}^{2}+l_{3}^{3}}}\right.$ の形

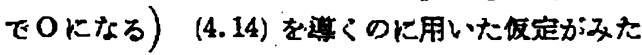
されない。 